\title{
Effective core potential ab initio calculations on main group heptoxides and large silicate systems
}

\author{
P.J.A. Ribeiro-Claro*, A.M. Amado \\ Unidade I and D “Química-Físca Molecular”, Departamento de Química, Faculdade de Ciências e Tecnologia, \\ Universidade de Coimbra, P-3049 Coimbra, Portugal
}

Received 7 June 1999; received in revised form 14 October 1999; accepted 1 November 1999

\begin{abstract}
The ab initio molecular structures for several main group heptoxides $\left(\mathrm{X}_{2} \mathrm{O}_{7}^{n-}, n=0,2,4\right)$ are calculated using effective core potentials at the HF and DFT (B3LYP) levels. Particular attention is given to the $\mathrm{X}-\mathrm{O}-\mathrm{X}$ bond angle, as this structural parameter is a key feature for the study of both heptoxides and larger derivatives, such as polysilicate systems. The extent of the $\mathrm{p}-\mathrm{d}$ interactions, which was found to be the main factor governing the magnitude of the $\mathrm{X}-\mathrm{O}-\mathrm{X}$ angle in transition metal heptoxides, does not play a significant role in the main group analogues.

In the cyclic polysilicate systems (up to 12 silicon atoms), the $\mathrm{Si}-\mathrm{O}-\mathrm{Si}$ bond angle is found to vary from $132^{\circ}$ in small rings to $150^{\circ}$ in the less strained systems. The results are in agreement with the experimental data available and its accuracy competes with that of results from much heavier all-electron calculations. (C) 2000 Elsevier Science B.V. All rights reserved.
\end{abstract}

Keywords: Heptoxides; Silicate; Zeolites; Molecular structures; Effective core potentials; B3LYP method

\section{Introduction}

In a recent publication [1] we have reported the calculated ab initio molecular structures and vibrational frequencies for the heptoxides of the VB, VIB and VIIB transition metal groups (general formula $\mathrm{X}_{2} \mathrm{O}_{7}^{n-}$, see Scheme 1 below), by using effective core potentials (ECP) at both HF and B3LYP levels. The relative energies of all optimized configurations, as well as the particular conformational preferences of each heptoxide, were presented and discussed. Special emphasis was given to the magnitude of the $\mathrm{X}-\mathrm{O}-\mathrm{X}$ bond angle, as it raised some attention in the last few years [1-13].

A general good agreement between the calculated

\footnotetext{
* Corresponding author. Tel./fax: +351-239826541.

E-mail address: claro@gemini.ci.uc.pt (P.J.A. Ribeiro-Claro).
}

and the reported experimental values, for both structural parameters and vibrational frequencies, was found by using the therein-selected ECP combination [1]. The overall results showed a clear tendency to linearity of the $\mathrm{X}-\mathrm{O}-\mathrm{X}$ framework on going both downwards a group and backwards a period (VIIB $\rightarrow$ VB), with the VB heptoxides presenting a perfectly centrosymmetric molecular geometry. The systematic behaviour of the $\mathrm{X}-\mathrm{O}-\mathrm{X}$ bond angle arises from sizedependent steric interactions, magnitude of the total heptoxide charge and extent of the $\mathrm{p}-\mathrm{d}$ interactions. Based on the calculated energy differences between the $2 \mathrm{p}$ orbitals of an $\mathrm{O}^{2-}$ anion and the valence $\mathrm{d}$ orbitals of the metal cation, it was concluded that this latter effect is particularly meaningful for the reported transition metal heptoxides [1].

The wide practical applications of polysilicate analogues, obtained by substitution of some silicon 


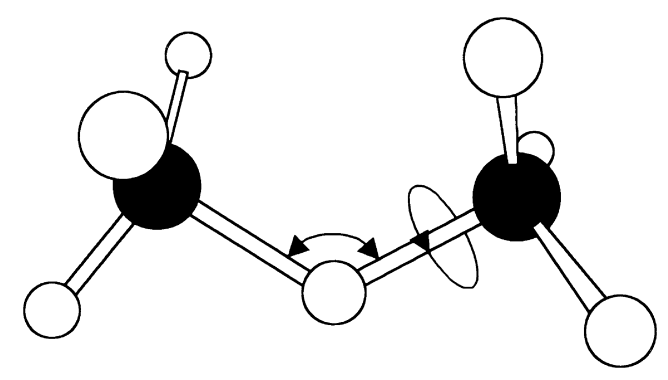

Scheme 1.

atoms by other type of elements of both main (Al, P, $\mathrm{Ge}, \mathrm{Sn}, \mathrm{Te}$, among others) and transition metal (e.g. V and $\mathrm{Ti}$ ) groups, have renewed the interest of the structure-property relationships of $\mathrm{X}-\mathrm{O}-\mathrm{X}$ containing systems. Several studies of large polysilicate analogues using ab initio methods at different levels of sophistication have recently been reported [14-18]. Such calculations are highly demanding in computational resources and its application as an additional laboratory tool requires the use of powerful computers. Thus, the evaluation of the accuracy and reliability of light ECP/basis set combinations is still of practical interest.

In this way, the purpose of the present study is twofold. Firstly, to determine the structural preferences of VA, VIA and VIIA main group heptoxides, following the previous report on the transition metal analogues [1]. Secondly, to evaluate the performance of the selected ECP-basis set combination for silicon containing systems, by comparing the optimized structures of some neutral cyclic polysilicon systems with reported experimental and/or higher level theoretical results available.

\section{Computational methodology}

The calculations were performed using the Gaussian 98w program package [19] on a Pentium II $300 \mathrm{MHz}$ computer with $288 \mathrm{MB}$ of RAM.

All the calculations on $\mathrm{X}_{2} \mathrm{O}_{7}^{n-}$ systems were performed by using the oxygen $\mathrm{ECP} /$ minimal valence basis set of Stevens et al. [20] deliberately augmented with a polarization d-type function $(\zeta=0.8$ [21]) which proved to be essential for the description of the $\mathrm{X}-\mathrm{O}-\mathrm{X}$ bond angle in this kind of system $[1,3-$
13]. It should be mentioned that the use of a doublezeta valence basis set for the oxygen atoms did not improve the quality of the results (see Ref. [1] and this work) and has been abandoned to keep the quality/ computational costs ratio as high as possible. The hydrogen atom was described by the standard 3-21G basis set [22], while for the remaining elements but the halogen atoms, the Hay and Wadt's ECP [23] with double-zeta split valence shell was used. This ECP has proven elsewhere [24] to yield good results for main group organometallic compounds.

In the particular case of the VIIA group elements, a d-type polarization function was added to the Hay and Wadt's double-zeta valence space $(\zeta=0.75,0.389$ and 0.266 for $\mathrm{Cl}, \mathrm{Br}$ and $\mathrm{I}$, respectively $[21,25]$ ) to overcome stability problems (e.g. in the absence of such polarization function the $\mathrm{Cl}_{2} \mathrm{O}_{7}$ molecule splits into three fragments during geometry optimization, a problem that is not overcome by additional improvement of the oxygen atom basis set). Additional test calculations using dichloride monoxide $\left(\mathrm{Cl}_{2} \mathrm{O}\right)$ showed that the inclusion of a d-type polarization function on the chlorine atom leads to a good agreement between the calculated and experimental structural parameters of $\mathrm{Cl}_{2} \mathrm{O}\left(168 \mathrm{pm}\right.$ and $111^{\circ}$ vs. $170 \mathrm{pm}$ and $111^{\circ}$ [26], respectively).

In order to account for the electron correlation effects, the widely used hybrid method denoted by B3LYP [27-32], which includes a mixture of HF and DFT exchange terms and the gradient-corrected correlation functional of Lee et al. [33], as proposed and parameterized by Becke [34], was used (with standard B3LYP options of G98w).

Several possible configurations were used as starting points (see Fig. 1 of Ref. [1]) and fully optimized at the HF and B3LYP levels. The order of the critical points $(\lambda=0$ for minima, $\lambda=1,2, \ldots$ for first and higher order saddle points) was evaluated at the HF level by computing the vibrational frequencies.

For the silicon containing systems, an additional d-type function $(\zeta=0.39)$ was included in the silicon atom basis set. The inclusion of this polarization function has been previously considered to be required on silicate derivatives [11-13], and it has been found to be the only additional requirement to obtain a good description of the neutral disilicate systems $\mathrm{H}_{3} \mathrm{Si}-\mathrm{O}-\mathrm{SiH}_{3}$ and $(\mathrm{OH})_{3} \mathrm{Si}-\mathrm{O}-\mathrm{Si}(\mathrm{OH})_{3}$ with the present ECP/basis set combination, 
Table 1

Calculated energy differences $\left(\Delta \mathrm{E} / \mathrm{kJ} \mathrm{mol}^{-1}\right)$ between the several optimized geometries, relative to the energy minimum for each heptoxide studied $(\mathrm{DFT}=\mathrm{B} 3 \mathrm{LYP})$. The number of calculated imaginary vibrational frequencies, $\lambda$ (order of the critical point $(0,1$ and 2 stand for minimum, first- and second-order saddle points, respectively)), are also included. As referred to in the experimental section, the valence shell basis set of the halogen atoms were augmented with a polarization function

\begin{tabular}{|c|c|c|c|c|c|c|c|c|c|c|c|c|c|c|c|}
\hline \multirow[t]{2}{*}{ Structure } & \multicolumn{3}{|l|}{$\mathrm{P}_{2} \mathrm{O}_{7}^{4-}$} & \multicolumn{3}{|l|}{$\mathrm{S}_{2} \mathrm{O}_{7}^{2-}$} & \multicolumn{3}{|l|}{$\mathrm{Cl}_{2} \mathrm{O}_{7}$} & \multicolumn{3}{|c|}{$\mathrm{As}_{2} \mathrm{O}_{7}^{4-}$} & \multicolumn{3}{|l|}{$\mathrm{Se}_{2} \mathrm{O}_{7}^{2-}$} \\
\hline & $\mathrm{HF}$ & $\lambda$ & DFT & $\mathrm{HF}$ & $\lambda$ & DFT & $\mathrm{HF}$ & $\lambda$ & DFT & $\mathrm{HF}$ & $\lambda$ & DFT & $\mathrm{HF}$ & $\lambda$ & DFT \\
\hline$C_{2}$ & 0.00 & 0 & 0.00 & 0.00 & 0 & 0.00 & 0.00 & 0 & 0.00 & 0.00 & 0 & 0.00 & 0.00 & 0 & 0.00 \\
\hline$C_{\mathrm{s}}$ & 0.09 & 1 & 0.20 & 1.43 & 1 & 0.89 & 4.45 & 1 & 3.19 & 0.05 & 1 & 0.17 & 0.73 & 1 & 0.58 \\
\hline$C_{2 \mathrm{v}(\mathrm{syn})}$ & 4.54 & 1 & 1.69 & 7.52 & 1 & 1.57 & 3.62 & 1 & 0.75 & 4.43 & 1 & 1.89 & 8.30 & 1 & 2.88 \\
\hline$C_{2 \mathrm{v}(\text { anti) }}$ & 6.94 & 2 & 4.24 & 23.63 & 2 & 10.27 & 28.12 & 2 & 17.11 & 6.06 & 2 & 4.09 & 17.80 & 2 & 10.34 \\
\hline$D_{3 \mathrm{~d}}$ & 9.44 & 1 & 11.69 & 71.83 & 1 & 59.54 & 123.20 & 1 & 115.76 & 6.90 & 1 & 10.84 & 50.79 & 1 & 50.03 \\
\hline \multirow[t]{3}{*}{$D_{3 \mathrm{~h}}$} & 12.84 & 2 & 13.51 & 74.28 & 2 & 60.63 & 123.68 & 1 & 116.25 & 10.25 & 2 & 12.71 & 53.50 & 2 & 51.34 \\
\hline & \multicolumn{3}{|l|}{$\mathrm{Br}_{2} \mathrm{O}_{7}$} & \multicolumn{3}{|c|}{$\mathrm{Sb}_{2} \mathrm{O}_{7}^{4-}$} & \multicolumn{3}{|l|}{$\mathrm{Te}_{2} \mathrm{O}_{7}^{2-}$} & \multicolumn{3}{|l|}{$\mathrm{I}_{2} \mathrm{O}_{7}$} & \multicolumn{3}{|l|}{$\mathrm{Bi}_{2} \mathrm{O}_{7}^{4-}$} \\
\hline & $\mathrm{HF}$ & $\lambda$ & DFT & $\mathrm{HF}$ & $\lambda$ & DFT & $\mathrm{HF}$ & $\lambda$ & DFT & $\mathrm{HF}$ & $\lambda$ & DFT & $\mathrm{HF}$ & $\lambda$ & DFT \\
\hline$C_{2}$ & 0.00 & 0 & 0.00 & 0.00 & 0 & 0.00 & 0.00 & 0 & 0.00 & 0.00 & 0 & 0.00 & 0.00 & 0 & 0.01 \\
\hline$C_{\mathrm{s}}$ & 1.36 & 1 & 1.94 & 0.00 & 1 & 0.01 & 0.03 & 1 & 0.17 & 0.34 & 1 & 0.34 & 0.00 & 1 & 0.00 \\
\hline$C_{2 \mathrm{v}(\mathrm{syn})}$ & 2.08 & 1 & 1.83 & 3.87 & 1 & 2.30 & 0.87 & 1 & a & 5.23 & 1 & 3.18 & 3.33 & 1 & 1.78 \\
\hline$C_{2 \mathrm{v}(\text { anti) }}$ & 10.16 & 2 & 12.79 & 3.98 & 2 & 3.28 & 1.30 & 2 & 9.42 & 10.11 & 2 & 8.14 & 3.43 & 2 & 2.70 \\
\hline$D_{3 \mathrm{~d}}$ & 31.15 & 1 & 47.57 & 0.67 & 1 & 4.95 & 1.81 & 1 & 29.40 & 28.75 & 1 & 36.08 & 0.53 & 1 & 5.15 \\
\hline$D_{3 \mathrm{~h}}$ & 31.02 & 1 & 47.35 & 4.12 & 2 & 7.02 & 2.15 & 2 & 31.32 & 30.04 & 2 & 36.78 & 3.55 & 2 & 6.84 \\
\hline
\end{tabular}

${ }^{\text {a }}$ Converged to $C_{2}$ symmetry during geometry optimization.

particularly in what concerns the oxygen bridging bond angle.

\section{Results and discussion}

\section{1. $\mathrm{X}_{2} \mathrm{O}_{7}^{n-}$ systems}

Table 1 shows the calculated energy differences between the several optimized geometries and the minimum energy configuration, found at the HF and B3LYP levels, for the several main group heptoxides herein considered. The number of imaginary frequencies $(\lambda)$ obtained at the HF level for each optimized structure is also included, showing that only one energy minimum (staggered $C_{2}$ configuration) was found for each heptoxide. However, some caution should be taken on this subject, as the lowest wavenumbers for several minima are quite low $\left(<10 \mathrm{~cm}^{-1}\right)$ and the HF energy difference between the lowest energy configurations is often smaller than a tenth of $\mathrm{kJ} \mathrm{mol}^{-1}$. In addition, the inclusion of the electron correlation effects leads to a general narrowing of the energy differences between the stationary points.

The calculated structural parameters obtained for the minimum energy configuration of each heptoxide considered, at both HF and DFT levels, are presented in Table 2, in comparison with experimental data available. A general overestimation of the bond lengths is observed for the B3LYP geometries. This problem seems to be related with the B3LYP approximation, possibly resulting from the neglect of dispersion interactions.

The agreement between the calculated and the experimental values is good, if we keep in mind that the ab initio calculations consider the isolated molecules and the experimental data refer to solid samples, in which the heptoxide structure is conditioned by the crystal packing (except for $\mathrm{Cl}_{2} \mathrm{O}_{7}$ ). The absence of the crystal environment is particularly critical for the multiply charged $\mathrm{X}_{2} \mathrm{O}_{7}^{4-}$ anions, as it will be discussed below.

The best system to evaluate the quality of the calculated structural parameters is $\mathrm{Cl}_{2} \mathrm{O}_{7}$, since both 
Table 2

Optimized parameters for the energy-minimum of each metal heptoxide studied. Experimental results are included, whenever existent (bond lengths are average values). Please note that, as referred to in the experimental section, the valence shell basis set of the halogen atoms were augmented with a d-type polarization function $\left(\mathrm{O}_{\mathrm{b}}\right.$ and $\mathrm{O}_{\mathrm{t}}$ stand for bridge and terminal oxygen respectively; DFT $\left.=\mathrm{B} 3 \mathrm{LYP}\right)$

\begin{tabular}{|c|c|c|c|c|c|c|c|}
\hline$X_{2} O_{7}^{n-}$ & & $\mathrm{X}-\mathrm{O}_{\mathrm{b}}(\mathrm{pm})$ & $\mathrm{X}-\mathrm{O}_{\mathrm{t}}(\mathrm{pm})$ & $\mathrm{O}_{\mathrm{b}}-\mathrm{X}-\mathrm{O}_{\mathrm{t}}\left({ }^{\circ}\right)$ & $\mathrm{O}_{\mathrm{t}}-\mathrm{X}-\mathrm{O}_{\mathrm{t}}\left({ }^{\circ}\right)$ & $\mathrm{X}-\mathrm{O}_{\mathrm{b}}-\mathrm{X}\left({ }^{\circ}\right)$ & Sym. \\
\hline \multirow[t]{4}{*}{$\mathrm{P}_{2} \mathrm{O}_{7}^{4-}$} & Calculated HF & 172 & 156 & $103-110$ & 112 & 148 & $C_{2}$ \\
\hline & Calculated DFT & 192 & 162 & $101-112$ & 112 & 146 & $C_{2}$ \\
\hline & Experimental $^{\mathrm{a}}$ & 161 & 152 & $101-110$ & $109-114$ & 133 & \\
\hline & & & & & & $143^{\mathrm{a}}$ & \\
\hline \multirow[t]{3}{*}{$\mathrm{As}_{2} \mathrm{O}_{7}^{4-}$} & Calculated HF & 180 & 167 & $103-110$ & 112 & 149 & $C_{2}$ \\
\hline & Calculated DFT & 197 & 173 & $101-112$ & 112 & 146 & $C_{2}$ \\
\hline & Experimental $^{\mathrm{b}}$ & 179 & 168 & $102-107$ & $111-118$ & 116 & \\
\hline \multirow[t]{2}{*}{$\mathrm{Sb}_{2} \mathrm{O}_{7}^{4-}$} & Calculated HF & 194 & 184 & $105-109$ & 113 & 161 & $C_{2}$ \\
\hline & Calculated DFT & 208 & 190 & $102-112$ & 112 & 150 & $C_{2}$ \\
\hline \multirow{2}{*}{$\mathrm{Bi}_{2} \mathrm{O}_{7}^{4-}$} & Calculated HF & 203 & 193 & $105-110$ & $112-113$ & 162 & $C_{2}$ \\
\hline & Calculated DFT & 218 & 198 & $105-114$ & 111 & 151 & $C_{2}$ \\
\hline \multirow[t]{3}{*}{$\mathrm{S}_{2} \mathrm{O}_{7}^{2-}$} & Calculated HF & 170 & 152 & $100-108$ & 114 & 126 & $C_{2}$ \\
\hline & Calculated DFT & 192 & 159 & 99-109 & 114 & 125 & $C_{2}$ \\
\hline & Experimental $^{\mathrm{c}}$ & 165 & 144 & $101-106$ & $113-116$ & 124 & \\
\hline \multirow[t]{2}{*}{$\mathrm{Se}_{2} \mathrm{O}_{7}^{2-}$} & Calculated HF & 178 & 163 & $101-107$ & 114 & 128 & $C_{2}$ \\
\hline & Calculated DFT & 196 & 169 & 99-109 & 114 & 124 & $C_{2}$ \\
\hline \multirow[t]{2}{*}{$\mathrm{Te}_{2} \mathrm{O}_{7}^{2-}$} & Calculated HF & 188 & 177 & $102-106$ & 114 & 136 & $C_{2}$ \\
\hline & Calculated DFT & 202 & 182 & 99-107 & $113-116$ & 128 & $C_{2}$ \\
\hline \multirow[t]{5}{*}{$\mathrm{Cl}_{2} \mathrm{O}_{7}$} & Calculated HF & 166 & 139 & 99-105 & 115 & 122 & $C_{2}$ \\
\hline & $\mathrm{HF} / 6-31 \mathrm{G}^{* \mathrm{~d}}$ & 168 & 140 & $99-105$ & 115 & 122 & $C_{2}$ \\
\hline & Calculated DFT & 180 & 145 & $97-105$ & $115-116$ & 117 & $C_{2}$ \\
\hline & $\mathrm{MP} 2 / 6-31 \mathrm{G}^{* \mathrm{~d}}$ & 180 & 145 & $97-105$ & 116 & 115 & $C_{2}$ \\
\hline & Experimental $^{\mathrm{e}}$ & 170 & 140 & $98-106$ & 115 & 119 & $C_{2 \mathrm{v}}$ \\
\hline \multirow[t]{2}{*}{$\mathrm{Br}_{2} \mathrm{O}_{7}$} & Calculated HF & 173 & 144 & $101-103$ & 116 & 129 & $C_{2}$ \\
\hline & Calculated DFT & 183 & 149 & $99-103$ & 116 & 120 & $C_{2}$ \\
\hline \multirow[t]{2}{*}{$\mathrm{I}_{2} \mathrm{O}_{7}$} & Calculated HF & 190 & 171 & $100-103$ & 116 & 130 & $C_{2}$ \\
\hline & Calculated DFT & 200 & 176 & $99-103$ & 116 & 124 & $C_{2}$ \\
\hline
\end{tabular}

${ }^{a} \mathrm{X}$-ray values for $\mathrm{Hg}_{2} \mathrm{P}_{2} \mathrm{O}_{7}$ [35]; value of $143^{\circ}$ was reported previously for $\mathrm{Co}_{2} \mathrm{P}_{2} \mathrm{O}_{7}$ [36].

${ }^{\mathrm{b}} \mathrm{X}$-ray values for $\mathrm{Na}_{4} \mathrm{Ce}\left(\mathrm{As}_{2} \mathrm{O}\right)_{7}$ [37]; values of 127 and $128^{\circ}$ are also encountered [38,39].

${ }^{c} \mathrm{X}$-ray values for $\mathrm{K}_{2} \mathrm{~S}_{2} \mathrm{O}_{7}$ [40].

${ }^{\mathrm{d}}$ All electron ab initio results [41].

${ }^{\mathrm{e}}$ Gas-phase electron diffraction value [42].

gas-phase experimental results [42] and higher level ab initio calculations [41] have been reported for this molecule. As it can be seen from Table 2, there is an excellent agreement between the present results and the reported $6-31 \mathrm{G}^{*}$ values, thus supporting the quality of the ECP/basis set chosen. In particular, the bond lengths and bond angles obtained at the B3LYP level are nearly identical to those reported from much heavier MP2/6-31G* calculations. The description of the experimental parameters is good, particularly that which concerns the bond angles. Interestingly, the experimental bond lengths of $\mathrm{Cl}_{2} \mathrm{O}_{7}$ are better reproduced by the non-correlated methods (even taken into account the different meanings of $r_{0}$ and $r_{\mathrm{e}}$ structures).

The relative importance of the $C_{2}$ and $C_{2 \mathrm{v}}$ structures of $\mathrm{Cl}_{2} \mathrm{O}_{7}$ deserves some attention. While X-ray diffraction results point to a $C_{2 \mathrm{v}}$ geometry in the crystal [43], both calculations (this work and previous all-electron results [41]) and gas-phase electron diffraction results [42] agree in a $C_{2}$ minimum for the isolated molecule. Since both structures $\left(C_{2}\right.$ and $C_{2 \mathrm{v}}$ ) are calculated to be separated by only $0.75 \mathrm{~kJ} \mathrm{~mol}^{-1}$ (at the B3LYP level), their relative energies can be easily reversed by crystal packing forces. 
By analysing the calculated values for the $\mathrm{X}-\mathrm{O}-\mathrm{X}$ angle in Table 2, it is obvious that its variation follows the same general trends previously observed for the transition metal heptoxides [1]. In fact, the main group heptoxides also display a general tendency for linearization of the $\mathrm{X}-\mathrm{O}-\mathrm{X}$ framework on going both downwards a group and backwards a period $(\mathrm{VIIA} \rightarrow \mathrm{VA})$. The comparison between the two sets of heptoxides (transition metal vs. main group) provides additional information concerning the factors governing the magnitude of the oxygen bridging angle. For the transition metal heptoxides [1], the observed trends were explained by three main effects: (i) total electronic charge of the heptoxide; (ii) metal atom size and (iii) $\pi$-bonding between the two filled $2 p$ orbitals of the bridging oxygen atom and the empty d orbitals of the metal atom. The extent of the $\mathrm{p}-\mathrm{d}$ interactions, which was concluded to be the dominant factor in the transition metal series [1], is not expected to play a significant role on the main group set. For instance, previous calculations on silicate derivatives show that a d-type function is required on the silicon atom, but only to polarize the $\mathrm{s}$ and $\mathrm{p}$ orbitals and give a better description of those orbitals at large distances from the nucleus $[4,11,13]$.

The present results are in agreement with this observation. The increase of the $\mathrm{X}-\mathrm{O}-\mathrm{X}$ bond angle downwards a group is much less pronounced in the main group heptoxides than in the transition metal analogues series (ca. $5^{\circ}$, compared with more than $20^{\circ}$, respectively). Such a small variation can be explained by the increasing size of the $\mathrm{X}$-atom along a group.

On the other hand, the main factor determining the increase of the bridging bond angle backwards each period can be evaluated by comparing the molecular structure of the fully charged VA anions with the structure of their protonated species $\mathrm{H}_{m} \mathrm{X}_{2} \mathrm{O}_{7}^{-4+m}$ $(m=1, \ldots, 4)$, whose net negative charge is progressively reduced. As expected, the lowest energy structures for the protonated species present intramolecular $\mathrm{XOH}$... OX hydrogen bonds, which become the dominant factor controlling the $\mathrm{X}-\mathrm{O}-\mathrm{X}$ bond angle. However, considering only the optimized structures not presenting this type of interactions, there is a ca. $25^{\circ}$ decrease of the $\mathrm{X}-\mathrm{O}-\mathrm{X}$ bond angle on going from the $\mathrm{X}_{2} \mathrm{O}_{7}^{4-}$ to the $\mathrm{H}_{2} \mathrm{X}_{2} \mathrm{O}_{7}^{2-}$ species. Further reduction of the net negative charge does not produce relevant changes, and the $\mathrm{H}_{2} \mathrm{X}_{2} \mathrm{O}_{7}^{2-}, \mathrm{H}_{3} \mathrm{X}_{2} \mathrm{O}_{7}^{-}$and $\mathrm{H}_{4} \mathrm{X}_{2} \mathrm{O}_{7}$ species have nearly identical $\mathrm{X}-\mathrm{O}-\mathrm{X}$ angles, close to the values observed for the neutral heptoxides of group VIIA $\left(\mathrm{Cl}_{2} \mathrm{O}_{7}, \mathrm{Br}_{2} \mathrm{O}_{7}\right.$ and $\left.\mathrm{I}_{2} \mathrm{O}_{7}\right)$. Thus, the large net electronic charge is the only factor determining the wide $\mathrm{X}-\mathrm{O}-\mathrm{X}$ bond angles calculated for the isolated main group VA heptoxides. This contrasts with the case of the transition metal heptoxides, for which linear $\mathrm{X}-\mathrm{O}-\mathrm{X}$ angles were observed for the VB anions - with the same net charge of the group VA anions-because of the presence of additional $\mathrm{d}-\mathrm{p}$ interactions [1].

\subsection{Silicon-containing systems}

As a first test for the performance of the selected $\mathrm{ECP} /$ basis set for silicon containing systems, the molecular structures of the neutral silicon analogues $\mathrm{H}_{3} \mathrm{Si}-\mathrm{O}-\mathrm{SiH}_{3}$ and $(\mathrm{OH})_{3} \mathrm{Si}-\mathrm{O}-\mathrm{Si}(\mathrm{OH})_{3}$ were determined. Fig. 1 shows the optimized structures for both systems compared with the reported theoretical and experimental data.

Both forms present a clear preference for a bent $\mathrm{Si}-$ $\mathrm{O}-\mathrm{Si}$ angle, in agreement with previous experimental and higher level ab initio calculations $[12,13,44]$. In the case of the - $\mathrm{OH}$ derivative, the occurrence of intramolecular hydrogen bond contacts in the isolated molecule leads to an $\mathrm{Si}-\mathrm{O}-\mathrm{Si}$ bond angle below $140^{\circ}$. It should be stressed that the current calculations yield an excellent description of the reported gas-phase diffraction structure of disiloxane [44], significantly better than the much heavier HF/6$31 \mathrm{G}^{*}$ calculations [13]. The better performance is notorious for the $\mathrm{Si}-\mathrm{O}-\mathrm{Si}$ bond angle, which is highly overestimated at the $\mathrm{HF} / 6-31 \mathrm{G}^{*}$ level $(\mathrm{Si}-\mathrm{O}-\mathrm{Si}$ of $169^{\circ}$ [13]) while it is perfectly described by the present HF calculations (and overestimated by just $3^{\circ}$ at the B3LYP level). This is particularly important for the extension of the present calculations to larger silicon containing systems. In fact, due to the well-known flexibility of the $\mathrm{Si}-\mathrm{O}-\mathrm{Si}$ framework, the correct prediction of the $\mathrm{Si}-\mathrm{O}-\mathrm{Si}$ bond angle is a key feature for the ab initio structural study of silicon systems.

Figs. 2 and 3 present the calculated structures for the cyclic trimeric and tetrameric siloxane analogues with hydrogen and chloro terminal atoms, respectively, 

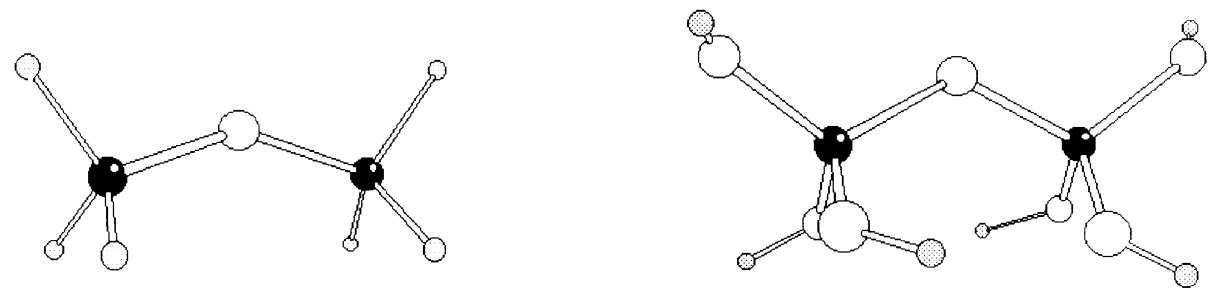

$\begin{array}{cccc}\text { HF } & \text { B3LYP } & \text { Exp. } & \text { MP2/6-31 } \boldsymbol{G}^{*} \\ 162 & 164 & 163 & 166 \\ 148 & 149 & 149 & 148 \\ 110 & 110 & 110 & 110 \\ 109 & 109 & 109 & \\ 144 & 147 & 144 & 144\end{array}$

$\begin{array}{ccccc} & \text { HF } & \text { B3LYP } & \text { Exp. } & \text { 6-31G* } \\ \mathbf{S i}-\mathbf{O}_{\mathbf{b}} & 162 & 164 & 162 & 162 \\ \mathbf{S i}-\bullet & 162 & 163 & & 162 \\ \mathbf{O}_{\mathbf{b}}-\mathbf{S i}-\bullet & 109 & 109 & & \\ \bullet-\mathbf{S i}-\bullet & 110 & 110 & & \\ \mathbf{S i}-\mathbf{O}_{\mathbf{b}}-\mathbf{S i} & 131 & 124 & 145 & 139\end{array}$

Fig. 1. Calculated structures of $\mathrm{H}_{3} \mathrm{Si}-\mathrm{O}-\mathrm{SiH}_{3}$ and $(\mathrm{OH})_{3} \mathrm{Si}-\mathrm{O}-\mathrm{Si}(\mathrm{OH})_{3}$, at the $\mathrm{HF}$ and $\mathrm{B} 3 \mathrm{LYP}$ levels, compared with the experimental data $[44,45]$ and higher level theoretical values $[12,13]$ available. Bond lengths are in pm and bond angles in degrees. $\bullet$ stands for terminal $\mathrm{H}$ atom or $\mathrm{OH}$ groups, respectively.

compared with the available experimental data and higher level calculation results. As it can be seen, there is a general agreement between the present results and the reported ones, at both levels of calculations, the B3LYP values being slightly better.
Present calculations and previous MP2/6-31G* calculations [47] yield nearly identical geometrical parameters for the cyclosiloxanes (Fig. 2). The notable exception is the $\mathrm{Si}-\mathrm{O}-\mathrm{Si}$ bond angle of the tetramer form, with calculated values of 144
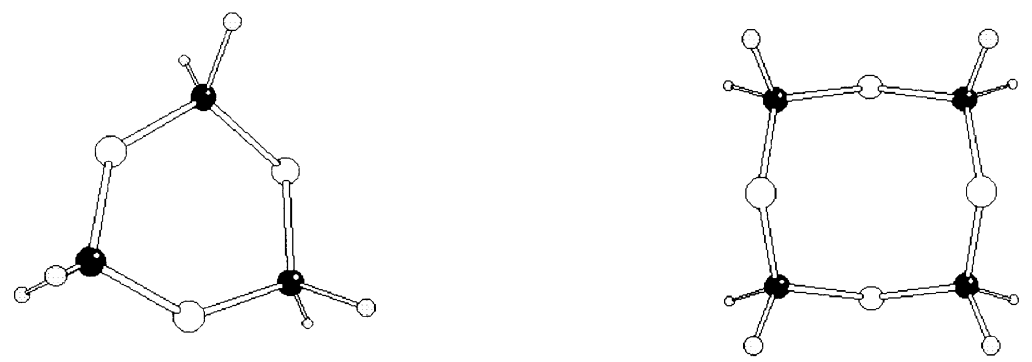

$\begin{array}{ccc}\text { HF } & \text { B3LYP } & \text { MP2/6-31G } \\ 163 & 165 & 166 \\ 147 & 148 & 148 \\ 108 & 108 & 108 \\ 133 & 132 & 132\end{array}$

$\begin{array}{ccccc} & \text { HF } & \text { B3LYP } & \text { Exp. } & \text { MP2/6-31G } \\ \text { Si - O } & 162 & 164 & 163 & 165 \\ \text { Si - H } & 147 & 148 & 148 & 148 \\ \text { O-Si - O } & 110 & 110 & 112 & 111 \\ \text { Si - O - Si } & 142 & 144 & 149 & 159\end{array}$

Fig. 2. Calculated structures of $\mathrm{Si}_{3} \mathrm{O}_{3} \mathrm{H}_{6}$ and $\mathrm{Si}_{4} \mathrm{O}_{4} \mathrm{H}_{8}$ at the $\mathrm{HF}$ and B3LYP levels, compared with the reported X-ray data for the tetramer form [46] and MP2/6-31G ${ }^{*}$ results [47] for both species (bond lengths are in pm and bond angles in degrees). Silicon, oxygen and hydrogen atoms are represented by black, white and grey circles, respectively. 


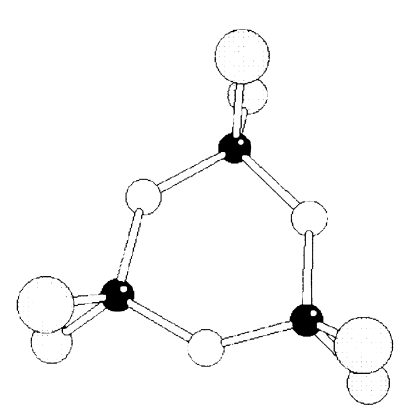

$\begin{array}{cccc}\text { HF } & \text { B3LYP } & \text { Exp. } & \text { MP2/6-31 } \boldsymbol{G}^{*} \\ 161 & 164 & 162 & 165 \\ 202 & 203 & 200 & 202 \\ 110 & 110 & 110 & 111 \\ 107 & 107 & 108 & 108 \\ 133 & 133 & 132 & 132\end{array}$

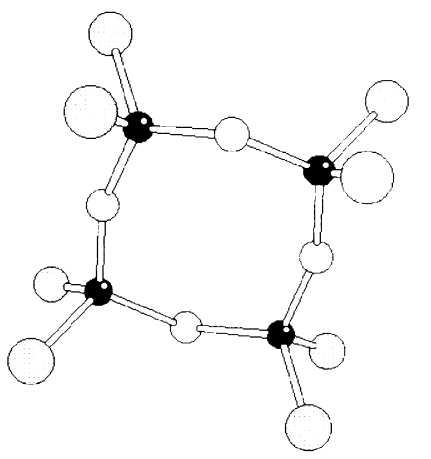

$\begin{array}{ccccc} & \text { HF } & \text { B3LYP } & \text { Exp. } & \text { MP2/6-31G* } \\ \text { Si }-\mathbf{O} & 160 & 162 & 159 & 163 \\ \mathbf{S i}-\mathbf{C l} & 201 & 203 & 200 & 202 \\ \mathbf{C I}-\mathbf{S i}-\mathbf{C I} & 110 & 110 & 110 & 111 \\ \mathbf{O}-\mathbf{S i}-\mathbf{O} & 110 & 110 & 110 & 110 \\ \mathbf{S i}-\mathbf{O}-\mathbf{S i} & 160 & 160 & 149 / 171 & 160\end{array}$

Fig. 3. Calculated structures of $\mathrm{Si}_{3} \mathrm{O}_{3} \mathrm{Cl}_{6}$ and $\mathrm{Si}_{4} \mathrm{O}_{4} \mathrm{Cl}_{8}$ at the HF and B3LYP levels compared with the reported X-ray data and MP2/6-31G* results [47] (bond lengths are in pm and bond angles in degrees). Silicon, oxygen and chloro atoms are represented by black, white and grey circles, respectively.

and $159^{\circ}$, respectively. The experimental value of $149^{\circ}$ [46] obtained at the B3LYP level for the $S_{4}$ crown-like configuration is found to be ca. $1.4 \mathrm{~kJ} \mathrm{~mol}^{-1}$ above the boat-like minimum shown in Fig. 2.

In the case of chlorosiloxanes (Fig. 3), the calculated structural parameters compare nicely with both the X-ray crystallographic data and the MP2/6-31G ${ }^{*}$ results, also reported in Ref. [47]. According to the $\mathrm{X}$-ray results, the trimer presents an almost planar $D_{3 \mathrm{~h}}$ geometry in the crystal with three equivalent $\mathrm{Si}-\mathrm{O}-\mathrm{Si}$ bond angles, while the tetramer assumes a chair-like configuration, with two different types of $\mathrm{Si}-\mathrm{O}-\mathrm{Si}$ bond angles. The MP2/6-31G* ${ }^{*}$ calculations yield planar structures for both forms, suggesting that the chair-like configuration of the tetramer arises from crystal packing constraints. As shown in Fig. 3, the calculated $\mathrm{Si}-\mathrm{O}-\mathrm{Si}$ bond angle for the planar trimer matches the experimental value of $132^{\circ}$, but the corresponding calculated value for the planar tetramer equals the average of the two experimental values $\left(149\right.$ and $\left.171^{\circ}\right)$.

As expected, based on ring constraint effects, the $\mathrm{Si}-\mathrm{O}-\mathrm{Si}$ and $\mathrm{O}-\mathrm{Si}-\mathrm{O}$ bond angles are more closed in the trimer than in the higher derivative. The difference is, however, more marked for the $\mathrm{Si}-\mathrm{O}-\mathrm{Si}$ angle, showing that the silicon atoms impose their preference towards regular tetrahedral co-ordination on the bridging oxygen atoms. The same effect was observed for the cyclic methylcyclosiloxane $\left(\left(\mathrm{OSiMe}_{2}\right)_{n}\right.$, with $\left.n=3-6\right)$ free molecules [48].

Fig. 4 shows the calculated structures of some spherosiloxanes with 6,8 and 12 silicon atoms. Spherosiloxanes are a group of silicon containing systems that, during recent years, have been extensively used as model compounds within zeolite and silicate chemistry, in what concerns their catalytic and analytical applications. One of those interesting compounds is the highly symmetrical octahydridosilasesquioxane molecule of $O_{\mathrm{h}}$ symmetry $\left(\mathrm{H}_{8} \mathrm{Si}_{8} \mathrm{O}_{12}\right.$, Fig. 4) for which several experimental results have been reported [49,51-54], as its $\mathrm{Si}_{8} \mathrm{O}_{12}$ core is often found in zeolites.

The comparison of the calculated and the experimental results for $\mathrm{H}_{8} \mathrm{Si}_{8} \mathrm{O}_{12}$ clearly shows that the current ECP combination is adequate for accurate calculations on this type of systems, comparing 


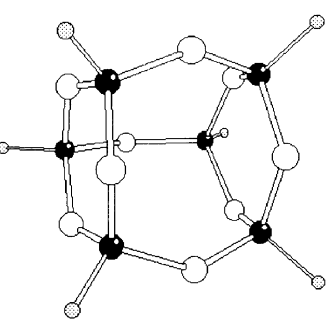

$\begin{array}{lcccc} & \text { HF } & \text { B3LYP } & \mathbf{6 - 3 1 G} & \text { NLDA } \\ \text { Si-O } & 162 & 165 / 164 & 164 / 163 & 168 \\ \text { O-Si-O } & 106 / 110 & 107 / 110 & 106 / 109 & 111 \\ \text { Si-O-Si } & 130 / 137 & 130 / 137 & 131 / 139 & 129 / 130\end{array}$
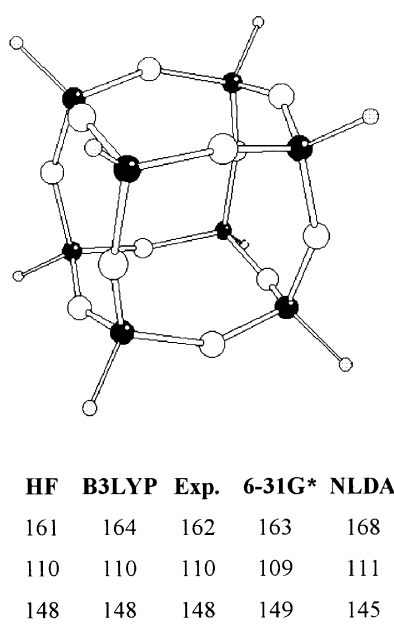

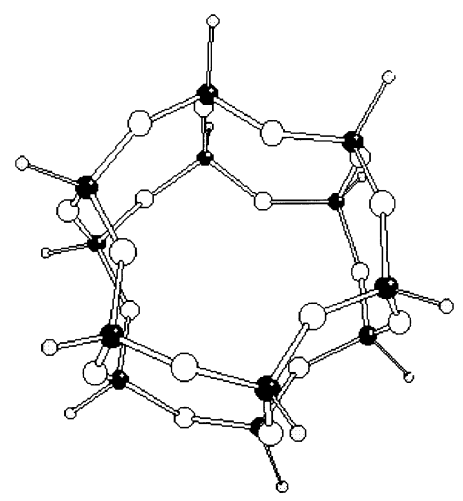

HF B3LYP 6-31G* NLDA

$161 \quad 164 / 163 \quad 163 / 162 \quad 167$

$110 / 109 \quad 110 / 109 \quad 110 / 109 \quad 113$

$144 / 148 \quad 147 / 150 \quad 150 / 155 \quad 163 / 143$

Fig. 4. Calculated structures of the oxo-spheroxanes $\mathrm{H}_{6} \mathrm{Si}_{6} \mathrm{O}_{9}, \mathrm{H}_{8} \mathrm{Si}_{8} \mathrm{O}_{12}$ and $\mathrm{H}_{12} \mathrm{Si}_{12} \mathrm{O}_{18}$ at the HF and B3LYP levels, compared with the gasphase diffraction data reported for the $\mathrm{H}_{8} \mathrm{Si}_{8} \mathrm{O}_{12}$ derivative [49] and the 6-31G ${ }^{*}$ and NLDA values reported for the three systems [18,50-54] (bond lengths are in pm and bond angles in degrees). Silicon, oxygen and hydrogen atoms are represented by black, white and grey circles, respectively. For the $\mathrm{H}_{6} \mathrm{Si}_{6} \mathrm{O}_{9}$ and $\mathrm{H}_{12} \mathrm{Si}_{12} \mathrm{O}_{18}$ systems, due to the presence of ring with different sizes, the differentiated values are shown as $3 R / 4 R$ and $4 R / 6 R$ ring, respectively, in accordance with the notation used elsewhere $[18,50]$.

with non-local density approximation (NLDA) [18] and $\mathrm{HF} / 6-31 \mathrm{G}^{*}$ [50] approaches. The $\mathrm{H}_{6} \mathrm{Si}_{6} \mathrm{O}_{9} \quad$ (of $D_{3 \mathrm{~h}}$ symmetry), $\mathrm{H}_{8} \mathrm{Si}_{8} \mathrm{O}_{12}$ and $\mathrm{H}_{12} \mathrm{Si}_{12} \mathrm{O}_{18}$ (of $D_{6 \mathrm{~d}}$ symmetry) systems (Fig. 4) follow the structural trends already observed for the previous systems. The $\mathrm{Si}-\mathrm{O}-\mathrm{Si}$ angle is particularly sensitive to the decrease of ring strain in the larger systems, while the remaining parameters are less sensitive. In fact, the $\mathrm{Si}-\mathrm{O}-\mathrm{Si}$ bond angle widens from $130^{\circ}$ in the three-membered rings of $\mathrm{H}_{6} \mathrm{Si}_{6} \mathrm{O}_{9}$ to $150^{\circ}$ in the four-membered rings of $\mathrm{H}_{8} \mathrm{Si}_{8} \mathrm{O}_{12}$ and $155^{\circ}$ in the six-membered rings of $\mathrm{H}_{12} \mathrm{Si}_{12} \mathrm{O}_{18}$, while the $\mathrm{O}$ $\mathrm{Si}-\mathrm{O}$ angle changes within the narrow $107-110^{\circ}$ range.

\section{Conclusions}

The practical application of the present ECP/ basis set combination to the structural studies on both main group heptoxides and large polysilicate systems is strongly supported by the results herein reported.

The calculated lowest energy structures of the main group heptoxides are in good agreement with the experimental data available, particularly in what concerns the relevant $\mathrm{X}-\mathrm{O}-\mathrm{X}$ bond angle parameter. The observed tendency to linearity of the $\mathrm{X}-\mathrm{O}-\mathrm{X}$ framework downwards a group and backwards a period can be explained by steric effects arising from the $\mathrm{X}$-atom size and from the net charge of the heptoxide. The (p-d)-type interactions, found to be the main factor in determining the structure of transition metal heptoxides [1], do not play a significant role in the main group analogues.

In what concerns the polysilicate systems, particular attention was given to the $\mathrm{Si}-\mathrm{O}-\mathrm{Si}$ bond angle parameter, as the wide variety of the reported values reflect the ease in which this angle can vary to meet the structural requirements. Calculated $\mathrm{Si}-\mathrm{O}-\mathrm{Si}$ bond angles ranging from $132^{\circ}$ in small rings to $150^{\circ}$ in less strained systems have been found. As reported elsewhere [2], the decrease of the $\mathrm{Si}-\mathrm{O}-\mathrm{Si}$ bond angle is generally followed by a lengthening of the $\mathrm{Si}-\mathrm{O}$ bonds, a behaviour that can be qualitatively related with the relative importance of the s- and p-orbitals in the oxygen atom hybridization. The results herein reported compare with the experimental 
data available, and their accuracy compete with that of the results from much heavier $6-31 \mathrm{G}^{*}$ calculations.

\section{Acknowledgements}

The authors acknowledge financial support from the Junta Nacional de Investigação Científica e Tecnológica (JNICT), Lisboa, Portugal.

\section{References}

[1] A.M. Amado, P.J.A. Ribeiro-Claro, J. Mol. Struct. (Theochem) 469 (1999) 191.

[2] G.M. Clark, R. Morley, Chem. Soc. Rev. 5 (1976) 269.

[3] C.A. Ernst, A.L. Allred, M.A. Ratner, M.D. Newton, G.V. Gibbs, J.W. Moskowitz, S. Topiol, Chem. Phys. Lett. 81 (1981) 424.

[4] J.P. Lopez, C.Y. Yang, C.R. Helms, J. Comp. Chem. 8 (1987) 198.

[5] J. Koput, Chem. Phys. 148 (1990) 299.

[6] J.B. Nicholas, R.E. Winans, R.J. Harrison, L.E. Iton, L.A. Curtiss, A.J. Hofinger, J. Phys. Chem. 96 (1992) 7958.

[7] B.T. Luke, J. Phys. Chem. 97 (1993) 7505.

[8] M.R. Bär, J. Sauer, Chem. Phys. Lett. 226 (1994) 405.

[9] J. Koput, J. Phys. Chem. 99 (1995) 15874.

[10] G.I. Csonka, J. Réffy, J. Mol. Struct. (Theochem) 332 (1995) 187.

[11] S. Grigoras, T.H. Lane, J. Comp. Chem. 8 (1987) 84.

[12] C.W. Earley, J. Comp. Chem. 14 (1993) 216.

[13] G.I. Csonka, M. Erdösy, J. Réffy, J. Comp. Chem. 15 (1994) 925.

[14] F. Haase, J. Sauer, J. Hutter, Chem. Phys. Lett. 226 (1997) 379.

[15] I. Stich, J.D. Gale, K. Terakura, M.C. Payne, J. Am. Chem. Soc. 121 (1999) 3292.

[16] J.-R. Hill, C.M. Freeman, B. Delley, J. Phys. Chem. A 103 (1999) 3772.

[17] A. Khodav, S.P. Bates, J. Dwyer, C.M. Windsor, N.A. Burton, Phys. Chem. Chem. Phys. 1 (1999) 507.

[18] K.-H. Xiang, R. Pandey, U.C. Pernisz, C. Freeman, J. Phys. Chem. B 102 (1998) 8704.

[19] M.J. Frisch, G.W. Trucks, H.B. Schlegel, G.E. Scuseria, M.A. Robb, J.R. Cheeseman, V.G. Zakrzewski, J.A. Montgomery, Jr., R.E. Stratmann, J.C. Burant, S. Dapprich, J.M. Millam, A.D. Daniels, K.N. Kudin, M.C. Strain, O. Farkas, J. Tomasi, V. Barone, M. Cossi, R. Cammi, B. Mennucci, C. Pomelli, C. Adamo, S. Clifford, J. Ochterski, G.A. Petersson, P.Y. Ayala, Q. Cui, K. Morokuma, D.K. Malick, A.D. Rabuck, K. Raghavachari, J.B. Foresman, J. Cioslowski, J.V. Ortiz, B.B. Stefanov, G. Liu, A. Liashenko, P. Piskorz, I. Komaromi,
R. Gomperts, R.L. Martin, D.J. Fox, T. Keith, M.A. AlLaham, C.Y. Peng, A. Nanayakkara, C. Gonzalez, M. Challacombe, P.M.W. Gill, B. Johnson, W. Chen, M.W. Wong, J.L. Andres, C. Gonzalez, M. Head-Gordon, E.S. Replogle, J.A. Pople, Gaussian 98, Revision A.3, Gaussian, Inc., Pittsburgh, PA, 1998.

[20] W.J. Stevens, H. Basch, M. Krauss, J. Chem. Phys. 81 (1984) 6026.

[21] W.J. Heyre, L. Radom, R.V.R. Schleyer, J.A. Pople, Ab initio Molecular Orbital Theory, Wiley, New York, 1986, p. 82.

[22] J.S. Binkley, J.A. Pople, W.J. Heyre, J. Am. Chem. Soc. 102 (1980) 939.

[23] W.R. Wadt, P.J. Hay, J. Chem. Phys. 82 (1985) 284.

[24] V. Jonas, G. Frenking, M.T. Reetz, J. Comp. Chem. 13 (1992) 935.

[25] M.J. Frisch, J.A. Pople, J.S. Binkley, J. Chem. Phys. 80 (1984) 3265 .

[26] M. Sugie, M. Ayabe, H. Takeo, C. Matsumura, J. Mol. Struct. $352 / 353$ (1995) 259.

[27] T.V. Russo, T.L. Martin, P.J. Hay, J. Phys. Chem. 99 (1995) 17085.

[28] T. Wagener, G. Frenking, Inorg. Chem. 35 (1998) 1805.

[29] F.A. Cotton, X. Feng, J. Am. Chem. Soc. 119 (1997) 7514.

[30] A. Ignaczak, J.A.N.F. Gomes, Chem. Phys. Lett. 257 (1996) 609.

[31] A. Ignaczak, J.A.N.F. Gomes, J. Electroanal. Chem. 420 (1997) 209.

[32] F.A. Cotton, X. Feng, J. Am. Chem. Soc. 120 (1998) 3387.

[33] C. Lee, W. Yang, R.G. Parr, Phys. Rev. B 37 (1988) 785.

[34] A. Becke, J. Chem. Phys. 98 (1993) 5648.

[35] M. Weil, R. Glaum, Acta Crystallogr. C 53 (1997) 1000.

[36] N. Krishnaniachari, C. Calvo, Acta Crystallogr. B 28 (1972) 2883.

[37] W. Belam, H. Bonghazala, T. Jonini, Acta Crystallogr. C 53 (1997) 397.

[38] C. Masquelier, F.D. Yvoire, N. Rodier, Acta Crystallogr. C 46 (1990) 1584.

[39] W. Belam, A. Briss, T. Jonini, Acta Crystallogr. C 53 (1997) 5.

[40] H. Lynton, M.R. Truter, J. Chem. Soc. (1960) 5112.

[41] S. Parthiban, B.N. Raghunandan, R. Sumathi, Spectrochim. Acta A 51 (1995) 2453.

[42] B. Beagley, Trans. Faraday Soc. 27 (1988) 1339.

[43] A. Simon, H. Borrmann, Angew Chem. Int. Ed. Engl. 27 (1988) 1339.

[44] A. Almenningen, A. Bastiansen, V. Ewing, K. Hedberg, M. Tretteberg, Acta Chem. Scand. 17 (1963) 2455.

[45] M. O'Keeffe, B. Domengès, G.V. Gibbs, J. Phys. Chem. 89 (1985) 2304.

[46] C. Glidewell, A.G. Robiette, G.M. Sheldrick, J. Chem. Soc., Chem. Commun. (1970) 931.

[47] R.G.A.R. Maclagan, M. Nieuwenhuyzen, C.J. Wilkins, B.E. Williamson, J. Chem. Soc., Dalton Trans. (1998) 2697.

[48] H. Oberhammer, W. Zeil, G. Fogarasi, J. Mol. Struct. 18 (1973) 309.

[49] Th P.E. Auf der Heyde, H.-B. Bürgi, H. Bürgy, K.W. Törnroos, Chimia 45 (1991) 38. 
[50] C.W. Earley, J. Phys. Chem. 98 (1994) 8693.

[51] J. Kowalewski, T. Nilsson, K.W. Törnroos, J. Chem. Soc., Dalton Trans. (1996) 1597.

[52] G. Calzaferri, R. Imhof, K. Törnroos, J. Chem. Soc., Dalton Trans. (1994) 3123.
[53] M. Bärtsch, P. Bornhauser, G. Calzaferri, R. Imhof, J. Phys. Chem. 98 (1994) 2817.

[54] C. Marcolli, P. Lainé, R. Bühler, G. Calzaferri, J. Phys. Chem. B101 (1997) 1171. 